\title{
Why does the Japanese Frail Aged Prefer to Stay in the Long Term Care Wards?
}

\author{
Shinya Matsuda ${ }^{1)}$ and Masayuki Tanaka ${ }^{2)}$ \\ 1) Department of Preventive Medicine and Community Health, University of Occupational and Environmental Health \\ 2) Department of Environmental Health, University of Occupational and Environmental Health
}

\begin{abstract}
In Japan, it is estimated that one third of hospitalized aged patient stay in the hospital because of social reasons not by medical needs. This type of hospitalization has long been criticized as the hospitalization by social reason, and been required to be solved for the appropriate use of medical resources. In order to solve this problem, we have conducted a patient survey in September 2006. We have developed a questionnaire and distributed it to all long term care hospitals in Fukuoka in September 2006. The number of investigated facilities is 220. All aged patients who had stayed in the institution more than $180 \mathrm{~d}$ were investigated. The total number of investigated frail aged is 9,115 . Among them the aged patients who were evaluated as "possible to discharge" were included into the analyses in order to investigate factors associated with their long LOS (Length of Stay). The number of cases for analyses was 4,862. The content of questionnaire is as follows: 1) Basic demographical data: age category, sex, family status (live alone or not), place of institution, 2) Health and ADL (Activities of Daily Living) status: Level of medical care needs, Level of ADL care needs, existence of dementia, medical diagnosis, 3) Social factors: willing to discharge, existence of fulfillment in life, comfort at home, economic status, social support from community. According to the results of logistic regression analysis, female, lack of assistance from social network, lack of comfort and safety at home, lack of meanings in life at home, address in Fukuoka region were associated with reluctance of discharge with statistical significance. Persons with dementia, lower ADL level, higher medical care needs showed a statistically significant positive wish for discharge. The present research has clarified that the aged with longer LOS are not necessarily persons with lower ADL level or severer dementia. They prefer to stay in hospital because they can expect a safe and comfortable daily life there. Therefore, in order to solve the problem of hospitalization by social reason, we have to organize a quality home care services as well as safety and reliable community environment.
\end{abstract}

Key words: hospitalization by social reasons, aged, QOL, home care services, Japan

\section{*ntroduction}

The very rapid graying of society is on going in Japan. It is estimated that the percentage of population over 65 yr old will be over $30 \%$ in $2025^{1)}$. Besides this

\section{Received: September 6, 2011}

Accepted: November 9, 2011

Correspondence: S. Matsuda, Department of Preventive Medicine and Community Health, University of Occupational and Environment Health, 1-1 Iseigaoka, Yahatanishiku, Kitakyushu, Fukuoka 807-8555, Japan

e-mail: smatsuda@med.uoeh-u.ac.jp very rapid ageing, the number of births has been decreasing. The TFR (Total Fertility Rate) has been decreasing from 1.75 in 1990 to 1.37 in 2008'). This ageing process has been accompanied with the change in disease structures; along with the economic development after the Second World War, the Japanese disease structure has dramatically changed from the acute diseases dominant pattern (i.e., infectious diseases) to the chronic diseases dominant one (i.e., cancer and cardio-vascular diseases). The chronic diseases require a longer period for its treatment. Furthermore most of the recent development in medical 
Table 1 Chronogical change in the structure of social security expenditures of Japan

\begin{tabular}{|c|c|c|c|c|c|c|c|}
\hline & \multirow{2}{*}{$\begin{array}{c}\text { Total } \\
\text { (billion yen) }\end{array}$} & \multicolumn{2}{|c|}{ Medical Care } & \multicolumn{2}{|c|}{ Pension } & \multicolumn{2}{|c|}{ Others* } \\
\hline & & (billion yen) & $(\%)$ & (billion yen) & $(\%)$ & (billion yen) & $(\%)$ \\
\hline 1965 & 1,604 & 914 & 57.0 & 351 & 21.9 & 339 & 21.1 \\
\hline 1970 & 3,524 & 2,076 & 58.9 & 855 & 24.3 & 593 & 16.8 \\
\hline 1975 & 11,772 & 5,706 & 48.5 & 3,887 & 33.0 & 2,179 & 18.5 \\
\hline 1980 & 24,763 & 10,693 & 43.2 & 10,471 & 42.3 & 3,599 & 14.5 \\
\hline 1985 & 35,668 & 14,248 & 39.9 & 16,915 & 47.4 & 4,505 & 12.7 \\
\hline 1990 & 47,205 & 18,350 & 38.9 & 24,065 & 51.0 & 4,790 & 10.1 \\
\hline 1995 & 64,726 & 24,059 & 37.2 & 33,499 & 51.8 & 7,169 & 11.0 \\
\hline 2000 & 78,119 & 25,995 & 33.3 & 41,201 & 52.7 & 10,923 & 14.0 \\
\hline 2005 & 87,915 & 28,109 & 32.0 & 46,293 & 52.7 & 13,513 & 15.3 \\
\hline
\end{tabular}

*: Others include the expenditures of ADL care for the frail elderly. Source: National Instituteof Population and Social Security Research.

Table 2 International comparaison of health resources (2003)

\begin{tabular}{|c|c|c|c|c|c|c|}
\hline Country & $\begin{array}{c}\text { Number of } \\
\text { beds per } 1,000 \\
\text { inhabitants }\end{array}$ & $\begin{array}{c}\text { Number of } \\
\text { doctors per } 100 \\
\text { beds }\end{array}$ & $\begin{array}{c}\text { Number of } \\
\text { doctors per } 1,000 \\
\text { inhabitants }\end{array}$ & $\begin{array}{c}\text { No of nurses } \\
\text { per } 100 \\
\text { beds }\end{array}$ & $\begin{array}{c}\text { No of nurses } \\
\text { per } 100,000 \\
\text { inhabitants }\end{array}$ & $\begin{array}{l}\text { Average } \\
\text { Length } \\
\text { of Stay }\end{array}$ \\
\hline Japan & 14.3 & $\begin{array}{c}13.7 \\
(2002)\end{array}$ & $\begin{array}{c}2 \\
(2002)\end{array}$ & $\begin{array}{c}54 \\
(2002)\end{array}$ & $\begin{array}{c}7.8 \\
(2002)\end{array}$ & 36.4 \\
\hline Germany & $\begin{array}{c}8.9 \\
(2002)\end{array}$ & $\begin{array}{c}37.6 \\
(2002)\end{array}$ & 3.4 & $\begin{array}{l}108.6 \\
(2002)\end{array}$ & 9.7 & $\begin{array}{c}10.9 \\
(2002)\end{array}$ \\
\hline France & 7.7 & $\begin{array}{c}42.5 \\
(2002)\end{array}$ & 3.4 & $\begin{array}{c}91.1 \\
(2002)\end{array}$ & 7.3 & 13.4 \\
\hline UK & 4.2 & $\begin{array}{c}49.7 \\
(2002)\end{array}$ & 2.2 & $\begin{array}{c}224 \\
(2002)\end{array}$ & 9.7 & 7.6 \\
\hline USA & 3.3 & $\begin{array}{c}66.8 \\
(2002)\end{array}$ & $\begin{array}{c}2.3 \\
(2002)\end{array}$ & $\begin{array}{c}233 \\
(2002)\end{array}$ & $\begin{array}{c}7.9 \\
(2002)\end{array}$ & 6.5 \\
\hline
\end{tabular}

Source: OECD Health data 2005.

technology focuses to chronic diseases, i.e., antihypertensive drugs and anti-diabetic drugs. As these new technologies do not completely eradicate the diseases but only control for a long period, the medical expenditures continue to increase. Furthermore, the longer life expectancy causes the increases of expenditures for pension and ADL (Activities of Daily Living) care. Table 1 shows the chronological change in expenditures structure of social insurance scheme in $\mathrm{Japan}^{2)}$. The expenditures for pension, medical care and other expenses including long-term care are 53\%, $32 \%$ and $15 \%$ in 2005 , respectively.

As the Japanese social insurance system is based on the transfer of money from the working generation to the retired aged, this demographic change makes it difficult to maintain the current system. In order to make the social insurance scheme sustainable in the coming aged society, Ministry of Health, Labour and Welfare (MHLW) has launched the Health care reform plan 2006. In which they have indicated the functional differentiation among the health facilities. It has long been criticized that the Japanese health care system heavily depends on the institutional care. Especially hospitalization of the frail aged is an important problem, because it occupies one third of health expenditures. According to the OECD statistics, length of stay (LOS) of the Japanese hospital is too much long compared with that of other countries as shown in Table $2^{3)}$.

Furthermore, it is estimated that one third of hos- 
pitalized aged patient stay in the hospital because of social reasons not by medical needs ${ }^{4}$. This type of hospitalization has long been criticized as the hospitalization by social reason, and been required to be solved for the appropriate use of medical resources.

There is a wide regional variation in the per capita health expenditures for the aged in Japan. For example, Fukuoka prefecture (the heaviest medical care using prefecture) shows 1.5 times higher expenditures than Nagano prefecture (the lightest medical care using prefecture $)^{5}$. Difference in LOS explains this wide regional difference ${ }^{5}$. According to the Health care reform plan 2006, each prefecture government is required to establish a regional health expenditure rationalization plan. For this reason the rationalization of LOS is one of the most important issues for Fukuoka local government in order to control the health expenditures for the aged.

As most of the aged patient and their family are usually reluctant to discharge, it is very important to know the factors associated with longer LOS among the aged patients in Fukuoka. For this purpose, we have conducted a patient survey in September 2006. In this article, we will present the research results and possible solutions for this problem.

\section{Population and Methods}

\section{Population}

We have developed a questionnaire and distributed it to all long term care hospitals in Fukuoka in September 2006. The number of investigated facilities is 220 . All aged patients who had stayed in the institution more than $180 \mathrm{~d}$ were investigated. In each institute, nurses are required to fulfill the questionnaire sheet using information in the medical record and by additional interview, if necessary. The total number of investigated frail aged is 9,115 . Among them the aged patients who were evaluated as "possible to discharge" were included into the analyses in order to investigate factors associated with their long LOS. The number of cases for analyses was 4,862. The content of questionnaire is as follows:

1) Basic demographical data: age category, sex, family status (live alone or not), place of institution (Fukuoka, Kitakyushu, Ken-nan, Chikuho Note)

2) Health and ADL status: Level of medical care needs, Level of ADL care needs, existence of dementia, medical diagnosis
3) Social factors: willing to discharge, existence of fulfillment in life, comfort at home, economic status, social support from community

\section{Statistical analyses}

At first, descriptive analyses were employed in order to know the basic characteristics of long LOS aged patients.

Based on the results of descriptive analyses, factors associated with longer stay were evaluated by the logistic regression analysis for the aged without family members $(1,208$ persons), and the aged with family (3,545 persons), respectively. The cases without full data were excluded from the analyses $(\mathrm{N}=109)$. There are not significant differences in base characteristics between included cases and excluded ones. The model for analysis is as follows:

Dependent variable: Willing to discharge $(\mathrm{Yes}=0$, $\mathrm{No}=1$ )

Independent variables: $\operatorname{Sex}($ Male $=0$, Female $=1)$, Age categories (65-74= 0.75 and more $=1)$, Existence of dementia (not dementia case $=0$, dementia case $=1$ ), ADL level (slight impairment $=0$, moderate impairment $=1$, severe impairment $=2$ ), Medical care needs ( light $=0$, moderate $=1$, heavy $=2$ ), place of residence (Ken-nan are=reference, dummy code for Fukoka area, Kitakyushu area, and Chikuho area), lack of existence of fulfillment ( $\mathrm{Yes}=1, \mathrm{No}=0)$, lack of comfort in home ( $\mathrm{Yes}=1, \mathrm{No}=0$ ), economic assistance (not necessary $=0$, necessary $=1$ ), lack of social support $(\mathrm{Yes}=1, \mathrm{No}=0)$.

\section{Results}

Table 3 shows the basic characteristics of investigated aged patients. The majority of the investigated aged are female $(75.1 \%)$, the old aged $(85.2 \%)$, and demented (90.6\%). Although they were evaluated as "less necessity of medical care, stable situation and thus possible to discharge", two thirds of them are more than moderately dependent and one third show necessity of moderate and high level of medical care. For the family status, a quarter is without family member. So far as the living condition at home, $13 \%$ of them feel the lack of comfort and safety, $7 \%$ reply the lack of economic assistance, $7 \%$ feel the lack of fulfillment of life and $4 \%$ are lack of assistance from the social network. Finally $7 \%$ of them show no willingness to discharge. 
Table 3 Basic characteristics of the investigated aged (Total number $=4,862$ )

\begin{tabular}{|c|c|c|}
\hline & $\mathrm{N}$ & $\%$ \\
\hline \multicolumn{3}{|l|}{ Age category } \\
\hline $65-74$ yr old & 719 & 14.8 \\
\hline $75 \mathrm{yr}$ old and more & 4,143 & 85.2 \\
\hline \multicolumn{3}{|l|}{$\operatorname{Sex}$} \\
\hline Male & 1,211 & 24.9 \\
\hline Hemale & 3,651 & 75.1 \\
\hline \multicolumn{3}{|l|}{ Demntia level } \\
\hline No dementia & 457 & 9.4 \\
\hline Slight demntia (rank I) & 397 & 8.2 \\
\hline Moderate dementia (rank II) & 996 & 20.5 \\
\hline Severe dementia (rank III) & 1,608 & 33.1 \\
\hline Very severe dementia (rank IV) & 1,039 & 21.4 \\
\hline Catastrophic (Rnak M) & 191 & 3.9 \\
\hline Unknown & 174 & 3.6 \\
\hline \multicolumn{3}{|l|}{ ADL dependency level } \\
\hline Level 1 (slight impairment) & 1,479 & 30.4 \\
\hline Level 2 (moderate impairment) & 1,985 & 40.8 \\
\hline Level 3 (severe impairment) & 1,398 & 28.8 \\
\hline \multicolumn{3}{|l|}{ Medical care needs level } \\
\hline Level 1 (slight) & 3,093 & 63.6 \\
\hline Level 2 (moderate) & 1,696 & 34.9 \\
\hline Level 3 (severe) & 73 & 1.5 \\
\hline \multicolumn{3}{|l|}{ Residential region } \\
\hline Fukuoka & 2,095 & 43.1 \\
\hline Ken-nan & 1,335 & 27.5 \\
\hline Chikuho & 347 & 7.1 \\
\hline Kitakyushu & 1,085 & 22.3 \\
\hline \multicolumn{3}{|l|}{ Family status } \\
\hline With family member & 3,545 & 72.9 \\
\hline Live alone & 1,208 & 24.8 \\
\hline Unknwon & 109 & 2.2 \\
\hline \multicolumn{3}{|l|}{ Comfortable and safety assured home } \\
\hline Yes & 4,227 & 86.9 \\
\hline No & 635 & 13.1 \\
\hline \multicolumn{3}{|c|}{ Existence of Fullfillment in daily life at home } \\
\hline Yes & 4,550 & 93.6 \\
\hline No & 312 & 6.4 \\
\hline \multicolumn{3}{|l|}{ Existence of ecnomic assistance } \\
\hline Yes & 4,532 & 93.2 \\
\hline No & 330 & 6.8 \\
\hline \multicolumn{3}{|c|}{ Existence of assistance from social network } \\
\hline Yes & 4,687 & 96.4 \\
\hline No & 175 & 3.6 \\
\hline \multicolumn{3}{|l|}{ Willing to discharge } \\
\hline Yes & 4,532 & 93.2 \\
\hline No & 330 & 6.8 \\
\hline
\end{tabular}

Table 4 shows the results of logistic regression analysis about factors associated with willing to discharge among the investigated aged patients with family members. Female, lack of assistance from social network, lack of comfort and safety at home, lack of meanings in life at home, address in Fukuoka region were associated with reluctance of discharge with statistical significance. Persons with dementia, lower ADL level, higher medical care needs showed a statistically significant positive wish for discharge.

Table 5 shows the results of logistic regression analysis about factors associated with willing to discharge among the investigated aged patients without family members. Female, lack of comfort and safety at home, and lack of economic assistance were associated with reluctance of discharge with statistical significance. Persons with dementia and lower ADL level showed a statistically significant positive wish for discharge.

\section{* Discussion}

The present research has clarified that the aged with longer LOS are not necessarily persons with lower ADL level or severer dementia. They prefer to stay in hospital because they can expect a safe and comfortable daily life there. Within the institution, they are assured basic needs such as meal services, bathing and toileting. In addition to these basic daily services, they periodically participate to rehabilitation and recreational activities organized by institution staffs. They can enjoy daily communication with other aged persons and younger staffs such as nurses, rehabilitation staffs, doctors, and nurse-aides. It can be said that hospital becomes a kind of comfortable community for them.

If they discharge and return to their home, it will be rather difficult for them to have such a comfortable social environment. Furthermore, the Japanese generous health insurance scheme covers most of the hotel cost. So that to live in hospital is a cheaper, safer and thus reasonable choice for the frail aged. This situation has long been criticized as a hospitalization by social reasons. Recently MHLW tries to introduce a discharge planning system into the long term care facilities but it does not work well. Reason is very simple. The aged patient and their family do not necessarily want it. With fewer children, more women working, and changing attitude toward family respon- 
Table 4 Results of logistic regression analysis about factors associated with willing to discharge among the investigated aged patients with family members $(\mathrm{N}=3,545)$

\begin{tabular}{|c|c|c|c|c|c|c|c|}
\hline & Beta & SE & Wald & $\mathrm{p}$-value & OR & $\begin{array}{c}\text { Lower } \\
95 \% \text { CI } \\
\text { of OR }\end{array}$ & $\begin{array}{c}\text { Higher } \\
95 \% \text { CI } \\
\text { of OR }\end{array}$ \\
\hline Age category & -0.083 & 0.215 & 0.149 & 0.699 & 0.92 & 0.60 & 1.40 \\
\hline Sex & 0.430 & 0.191 & 5.063 & 0.024 & 1.54 & 1.06 & 2.24 \\
\hline Dementia & -0.451 & 0.213 & 4.463 & 0.035 & 0.64 & 0.42 & 0.97 \\
\hline ADL level & -0.839 & 0.118 & 50.847 & 0.000 & 0.43 & 0.34 & 0.54 \\
\hline Medical care needs & -0.335 & 0.167 & 4.043 & 0.044 & 0.72 & 0.52 & 0.99 \\
\hline Lack of assistance from $\mathrm{SN}$ & 0.635 & 0.308 & 4.239 & 0.040 & 1.89 & 1.03 & 3.45 \\
\hline Lack of comfort and safety at home & 0.537 & 0.195 & 7.631 & 0.006 & 1.71 & 1.17 & 2.51 \\
\hline Lack of fullfillment in daily laife at home & 1.130 & 0.224 & 25.554 & 0.000 & 3.10 & 2.00 & 4.80 \\
\hline Lack of economic assistence & -0.098 & 0.292 & 0.114 & 0.736 & 0.91 & 0.51 & 1.61 \\
\hline Dummy for Fukuoka region & 0.532 & 0.194 & 7.509 & 0.006 & 1.70 & 1.16 & 2.49 \\
\hline Dummy for Kitakyushu region & 0.294 & 0.228 & 1.654 & 0.198 & 1.34 & 0.86 & 2.10 \\
\hline Dummy for Chikuho region & 0.563 & 0.315 & 3.203 & 0.074 & 1.76 & 0.95 & 3.25 \\
\hline Constant & -1.633 & 0.717 & 5.190 & 0.023 & 0.20 & 0.05 & 0.80 \\
\hline
\end{tabular}

Dependent variable: Willing to discharge $(\mathrm{Yes}=0, \mathrm{No}=1)$.

Independent variables: Sex (Male $=0$, Female $=1)$, Age categories $(65-74=0,75$ and more $=1)$, Existence of dementia (not dementia case $=0$, dementia case $=1$ ), ADL level (slight impairment $=0$, moderate impairment $=1$, severe impairment $=2$ ), Medical care needs $($ slight $=0$, moderate $=1$, heavy $=2$ ), place of residence (Ken-nan are $=$ reference, Fukoka area, Kitakyushu area, and Chikuho area), lack of existence of fulfillment ( $\mathrm{Yes}=1, \mathrm{No}=0)$, lack of comfort in home (Yes=1, $\mathrm{No}=0$ ), economic assistance (not necessary $=0$, necessary $=1$ ), lack of assistance from social network $\left(\mathrm{Yes}=1, \mathrm{No}_{\mathrm{O}}=0\right)$.

Table 5 Results of logistic regression analysis about factors associated with willing to discharge among the investigated aged patients without family members $(\mathrm{N}=1,208)$

\begin{tabular}{|c|c|c|c|c|c|c|c|}
\hline & Beta & SE & Wald & p-value & OR & $\begin{array}{c}\text { Lower } \\
95 \% \text { CI } \\
\text { of OR }\end{array}$ & $\begin{array}{c}\text { Higher } \\
95 \% \text { CI } \\
\text { of OR }\end{array}$ \\
\hline Age category & 0.657 & 0.354 & 3.438 & 0.064 & 1.93 & 0.96 & 3.86 \\
\hline Sex & 0.716 & 0.310 & 5.319 & 0.021 & 2.05 & 1.11 & 3.76 \\
\hline Dementia & -0.637 & 0.257 & 6.165 & 0.013 & 0.53 & 0.32 & 0.87 \\
\hline ADL level & -0.744 & 0.165 & 20.366 & 0.000 & 0.48 & 0.34 & 0.66 \\
\hline Medical care needs & 0.213 & 0.205 & 1.082 & 0.298 & 1.24 & 0.83 & 1.85 \\
\hline Lack of assistance from SN & 0.260 & 0.365 & 0.508 & 0.476 & 1.30 & 0.63 & 2.65 \\
\hline Lack of comfort and safety at home & 0.704 & 0.279 & 6.369 & 0.012 & 2.02 & 1.17 & 3.49 \\
\hline Lack of fullfillment in daily laife at home & 0.520 & 0.339 & 2.358 & 0.125 & 1.68 & 0.87 & 3.27 \\
\hline Lack of economic assistence & 0.829 & 0.287 & 8.323 & 0.004 & 2.29 & 1.30 & 4.02 \\
\hline Dummy for Fukuoka region & 0.383 & 0.279 & 1.884 & 0.170 & 1.47 & 0.85 & 2.53 \\
\hline Dummy for Kitakyushu region & 0.249 & 0.311 & 0.640 & 0.424 & 1.28 & 0.70 & 2.36 \\
\hline Dummy for Chikuho region & 0.231 & 0.424 & 0.295 & 0.587 & 1.26 & 0.55 & 2.89 \\
\hline Constant & -4.507 & 1.146 & 15.454 & 0.000 & 0.01 & 0.00 & 0.10 \\
\hline
\end{tabular}

Dependent variable: Willing to discharge ( $\mathrm{Yes}=1, \mathrm{No}=0$ ).

Independent variables: $\operatorname{Sex}($ Male $=0$, Female $=1$ ), Age categories $(65-74=0,75$ and more $=1$ ), Existence of dementia (not dementia case $=0$, dementia case $=1$ ), ADL level (slight impairment $=0$, moderate impairment $=1$, severe impairment $=2$ ), Medical care needs ( $\operatorname{light}=0$, moderate $=1$, heavy $=2$ ), place of residence $($ Ken-nan are $=$ reference, Fukoka area, Kitakyushu area, and Chikuho area), lack of existence of fulfillment $(\mathrm{Yes}=1, \mathrm{No}=0)$, lack of comfort in home (Yes=1, $\mathrm{No}=0$ ), economic assistance (not necessary $=0$, necessary $=1$ ), lack of assistance from social network $($ Yes $=1, \mathrm{No}=0)$. 
sibilities, the traditional system of informal care-giving at home is widely perceived as impossible to maintain. This is the most important reason for the introduction of the Long Term Care Insurance (LTCI) in 2000. One of the objectives of LTCI is the de-institutionalization of ADL care. At the moment of introduction of LTCI (April 2000), 520,000 aged were institutionalized, and 970,000 aged received homebased ADL care services ${ }^{6}$. On monetary base, these figures correspond to 195.4 billion yen (1.95 billion USD; 100 yen $=1$ USD) to institutional care and 97.6 billion yen ( 0.98 billion USD) to home-based care. Six years after, in December 2006, the number of aged persons who received institutional care and homebased care increased up to 800,000 and 2,560,000, respectively. On monetary base, these figures correspond to 210.0 billion yen ( 2.10 billion USD; 100 yen $=1 \mathrm{USD}$ ) to institutional care and 245.6 billion yen (2.46 billion USD) to home-based care. Even though the increase rate of institutional care has been relatively controlled both for the number of aged and cost, the government considers there is still a room for rationalization.

By the 2006 Health care reform, the government tries to further promote the home care. MHLW has largely decreased the tariff for long-term care beds intending to decrease this type of beds. Decreased beds are recommended to be transformed to a new type of residence for the aged; such as assisted living and nursing home. However, Japan Medical Association continues to strongly resist this reform partly because of shortage of community care services to cover the discharged persons and partly because of financial reasons.

But it will be reasonable to strengthen the home care system in order to prepare the coming highly aged society where 1.7 million deaths will occur annually. As Anezaki indicated, more than $80 \%$ of Japanese die at hospital today. However, it is not possible to equip institutional care for 1.7 million deaths. It is an emergent problem how to prepare the quality home care for the coming highly aged society. It will be difficult to realize it unless we prepare supportive environment for the frail elderly in the community. As our present results indicated, in addition to "core" medical services, it is required to organize a variety of associated services such as ADL care services (including meal services), logistic services, living environment arrangement, etc. If not, this reform will cause a large cost shift from public insurance to patient and their family.

Today two thirds of aged families are single or aged-couple households in Japan. This rapid demographic change makes it difficult to re-establish a traditional type of home care that depends on the family member for care-giving. In addition, along with the socio-cultural changes during the post-bubble economy era during $1990 \mathrm{~s}$, the traditional association based on kinship, living place and working place has lost its power. As traditional informal care cannot be expected today, we have to develop a new type of informal community care.

But solutions are not straightforward, because this problem is closely related to social divide. After the end of babble economy, social class divide has become a big social issue in Japan. Under the Koizumi (Former Prime Minister; 2001-2006) doctrine, social reforms have been done under the neo-liberal way of thinking. The de-regulation of labor market has resulted in the increase of part-time workers who were formerly full-time workers. Not small number of them cannot earn money enough to pay tax and contribution for social insurance scheme. This situation is just like a time bomb for the future social security system of Japan. Without enough income in the old age, one cannot receive the ADL care that is offered in the above mentioned "new residence".

The de-regulation of health market has made it possible for the private for-profit organization to construct a variety of ADL care services. Formerly these kinds of services were provided by the public sector. They constructed very well equipped assisted livings targeting for the rich aged. This kind of facility cannot be used by the aged people to whom our current research has focused.

Some favorable movement is also beginning. Some medical facilities have constructed informal health and social services. For example, there is a community restaurant so called "Asameshi-Shokudo" in a small town in Aomori prefecture, the Northernmost region of Honshu islands ${ }^{7}$. This restaurant is constructed by a private doctor as NPO (Non-profit Organization). The main purpose of this restaurant is to improve the QOL (Quality of Life) level of aged people. The restaurant offers the old peoples an opportunity not only to have warm and variable dishes but also to communicate with others. This example shows one possibility to promote a new community move- 
Table 6 Ageing situation of four areas of Fukuoka prefecture

\begin{tabular}{|c|c|c|c|c|c|}
\hline & \multirow[t]{2}{*}{ Total } & \multicolumn{2}{|c|}{$65 \mathrm{yr}$ old and more } & \multicolumn{2}{|c|}{$75 \mathrm{yr}$ old and more } \\
\hline & & $\mathrm{N}$ & $\%$ & $\mathrm{~N}$ & $\%$ \\
\hline Fukuoka & $2,319,702$ & 382,081 & $16.5 \%$ & 170,058 & $7.3 \%$ \\
\hline Kitakyushu & $1,327,351$ & 310,035 & $23.4 \%$ & 144,209 & $10.9 \%$ \\
\hline Ken-nan & 953,720 & 223,957 & $23.5 \%$ & 111,244 & $11.7 \%$ \\
\hline Chikuho & 460,542 & 117,515 & $25.5 \%$ & 59,759 & $13.0 \%$ \\
\hline Total & $5,061,315$ & $1,033,588$ & $20.4 \%$ & 485,270 & $9.6 \%$ \\
\hline
\end{tabular}

Source: Fukuoka prefecture (2008).

ment for the frail population based on the health facilities. As our present research has indicated, the medical facility offers not only medical but also social services for the frail aged. Therefore, it is a very interesting idea that a medical facility extends its functions to the community based services. Compared with other developed countries, the culture of donation and volunteer activity are relatively under-developed in Japan. The Aameshi-shokudo restaurant case suggests that a medical institution will be able to contribute to foster such culture.

Another option of solutions is to develop a Hospital-at-home care program ${ }^{8)}$. Hospital at home care provides health care for the patients who would otherwise require hospital stay. Typically patients receive a daily nurse visits and periodical consultation by hospital physician. This type of service has been developed in the occidental countries, and very new for Japan and other Asian countries. Along with the rapid ageing of Asian societies, we have to develop alternatives to in-patient care. The Hospital-at-home care is worth to be tested in the Asian context.

Aged society is the society with more persons who needs medical and social services, but available resources are limited. With fewer children, more women working, and changing attitude toward family responsibilities, the traditional system of formal and informal care-giving is widely perceived as inadequate to take care of the increasing number of the frail elderly. This is the same future for most of the other Asian countries. There has been no absolute solution suggested up to now. Some internationally collaborative studies on this issue will be expected to share the knowledge and experiences.

\section{References}

1) National Institute of Population and Social Security Research: Population Statistics of Japan 2008. http:/ /www.ipss.go.jp/p-info/e/psj2008/PSJ2008.pdf. (access 23 August 2010).

2) National Institute of Population and Social Security Research: Social Security Expenditures. http:// www.ipss.go.jp/site-ad/index_Japanese/security.html. (access 23 August 2010).

3) OECD: Health data 2005 (2005).

4) Ministry of Health, Labour and Welfare: Inter-rim report of research on lump-sum payment system for the long term in-patient services 2006. (28 March 2007). http://www.mhlw.go.jp/shingi/2007/05/dl/ s0530-7b.pdf . (access 23 August 2010).

5) Ministry of Health, Labour and Welfare: White paper of Health, Labour and Welfare 2005. http:// www.mhlw.go.jp/wp/hakusyo/kousei/05/dl/1 2n.pdf. (access 23 August 2010).

6) Ministry of Health, Labour and Welfare: Report of Long-term Care Insurance 2006, http:// www.mhlw.go.jp/topics/kaigo/osirase/jigyo/06/dl/ 01.pdf. (access 23 October 2008).

7) Ikiiki Asamushi: http://www.ikiiki-asamushi.net/ asameshi-syokudou.html. (access 23 October 2008).

8) Leff B, Burton L, Mader SL, Naughton B, Burl J, Inouye SK, et al.: Hospital at home: Feasibility and outcomes of a program to provide hospital-level care at home for acutely ill older patients. Ann Intern Med 143, 798-809 (2005).

\section{Note: About Fukuoka prefecture}

Japan composes of 47 prefectures, each of which is an independent local government with its own administrative office and Diet. Fukuoka prefecture is located at the west tip of Japan. The total population 
is about five million, the ninth largest prefecture of Japan. The climate is an oceanic type with four distinct seasons. There are 66 local communities (cities, towns and villages) in Fukuoka. These communities could be grouped into four zones according to their characteristics. There are two urban zones and two rural zones. The two urban zones located around two large cities with million inhabitants, Fukuoka and Kitakyushu. Fukuoka is the center of commercial and political activity and Kitakyushu is the industrial center. The central part of prefecture, called Chikuho area is the ex-coal mining zone where many social problems, i.e., high unemployment rate and school violence could be found. The fourth zone is Ken-nan area where there still remains a traditional Japanese lifestyle with many agricultural households and extended family. As shown in Table 6, the ageing of society is much advanced in Chikuho area ( $\%$ of 65 years old and more $=25.5 \%, \%$ of $75 \mathrm{yr}$ old and more $=13.0 \%$ ), followed by Ken-nan $(23.5 \%$ and $11.7 \%$, respectively), Kitakyushu (23.4\% and 10.9\%), and Fukuoka (16.5\% and $7.3 \%)$. 